\title{
LÍNGUA ESPANHOLA E UNATI/PE: FORTALECENDO LAÇOS DE AMIZADES
}

\author{
SPANISH LANGUAGE AND UNATI / PE: STRENGTHENING BONDS OF \\ FRIENDSHIPS
}

\section{LENGUA ESPAÑOLA Y UNATI/PE: FOTALECIENDO LAZOS DE AMISTAD}

Marina Holanda Kunst*

\begin{abstract}
Resumo: Atualmente verifica-se uma mudança significativa no perfil demográfico da população brasileira. O Brasil apresenta, segundo o IBGE, cerca de $9 \%$ da população, o que representa 15 milhões de idosos. Pela projeção do mesmo Instituto, o Brasil em 2025 será constituído por 34 milhões de idosos, aproximadamente 15\% da população. Segundo o Estatuto do Idoso, Lei 1.0741/03, considera-se idoso, as pessoas com 60 anos ou mais. Portanto, na perspectiva de que todos devem estar preparados para enfrentar e solucionar a problemática do envelhecimento populacional, a Universidade Federal de Pernambuco criou no ano de 2002, a Universidade Aberta de Terceira idade, que representa um espaço de convivência em grupo, com estímulo à participação ativa do idoso, valorização de suas potencialidades e talentos, além de se constituir em um espaço de prática para o estudo do envelhecimento, nas diversas áreas do conhecimento. Assim, neste texto faz-se uma análise histórica da evolução da criação das universidades abertas da terceira idade sob o prisma mundial e brasileiro culminando com a criação da citada Universidade na Universidade Federal de Pernambuco e referenciando os laços de amizades construídos a partir das aulas de língua espanhola. Observou-se, enfim, que foi necessário levar em conta a diminuição da acuidade auditiva, o incômodo ao se expor diante de uma habilidade que não domina, a dosagem das atividades que envolvam oralidade, a tendência do uso da língua materna nas discussões em grupo, o não interesse pela tarefa de casa e o mais importante, o querer manter o contato após as aulas e do curso.
\end{abstract}

Palavras-chave: Espanhol. Amizade. UnATI.

Abstract: Currently there is a significant change in the demographic profile of the Brazilian population. According to the IBGE, Brazil presents about 9\% of the population, which represents 15 million elderly people. By the projection of the same Institute, Brazil in 2025 will be constituted by 34 million elderly people, approximately $15 \%$ of the population. According to the Statute of the Elderly, Law 1.0741 / 03, it is considered elderly, people aged 60 or over. Therefore, in view of the fact that everyone must be prepared to face and solve the problem of population aging, the Federal University of Pernambuco created in 2002 the Open University of the Third Age, which represents a space for coexistence in a group, by stimulating the active participation of the elderly, valorization of their potentialities and talents, besides being a space of practice for the study of aging, in the various areas of knowledge. Thus, in this text a historical analysis of the evolution of the creation of open universities of the third age under the world and Brazilian prism culminating with the creation of the mentioned University in the Federal University of Pernambuco and referencing the bonds of friendships built from Spanish language lessons. It was observed, finally, that it was necessary to take into account the decrease of hearing acuity, the nuisance to be exposed on a skill that is not dominated, the dosage of activities involving speaking,

* Bacharel em Economia Doméstica pela Universidade Federal Rural de Pernambuco. Mestranda em Desenvolvimento Urbano pela Universidade Federal de Pernambuco. Professora da Universidade Aberta para a Terceira Idade, no curso de Espanhol. E-mail: marinakunst7@hotmail.com 
the tendency of the use of the mother tongue in the group discussions, the lack of interest in homework and most importantly, the desire to keep in touch after class and the course.

Keywords: Spanish. Friendship. UnATI.

Resumen: Actualmente existe un cambio significativo en el perfil demográfico de la población. El Brasil presenta, de acuerdo con el IBGE, alrededor del 9\% de la población, 15 millones de personas mayores. En la proyección del mismo Instituto, el Brasil en 2025 constará con 34 millones de personas de edad avanzada, aproximadamente el 15\% de la población. De acuerdo con el Estatuto do Idoso, Ley 1.0741/03, se consideran personas mayores, las personas con 60 años o más. Por lo tanto, frente a la perspectiva de que todo el mundo debe estar preparado para enfrentar y resolver los problemas de envejecimiento de la población, la Universidad Federal de Pernambuco creó en el año 2002, la Universidad Abierta de la Tercera Edad, que representa a un espacio de convivencia en grupo, con la estimulación a la participación activa de las personas mayores, la valoración de su potencial y talentos, además de estar en un espacio de práctica para el estudio del envejecimiento, en diversas áreas del conocimiento. De esta forma, este documento hace un análisis histórico de la evolución de la creación de universidades abiertas de la tercera edad en el mundo y el nivel brasileño que culminó con la creación de la dicha Universidad en la Universidad Federal de Pernambuco y haciendo referencia a los lazos de amistad construidos a partir de las clases de idioma español. En fin, fue necesario tener en cuenta la reducción de la agudeza auditiva, la incomodidad de ser expuestos ante una habilidad que no dominan, la dosificación de las actividades que implican hablar, la tendencia a la utilización de la lengua materna en las discusiones de grupo, el desinterés por la tarea de casa y lo más importante, el querer mantenerse en contacto después de clases y del curso.

Palabras claves: Español. Amistad. UnATI

\section{Introdução}

Hoje, um dos desafios do mundo contemporâneo refere-se ao fenômeno do envelhecimento. No Brasil, a população de idosos tem desabrochado de forma acelerada. As previsões demográficas avaliam que, nos próximos anos, haverá o dobro de pessoas idosas no Brasil. (OLIVEIRA, 2010).

No entanto, é preciso garantir a esta parcela da sociedade um mínimo de condições na melhoria da qualidade de vida, proporcionando-lhes o resgate da cidadania, de modo que o idoso possa estar engajado socialmente, participando da vida familiar e da comunidade. (GOMES; LOURES; ALENCAR, 2005).

Portanto, torna-se fundamental considerar a capacidade dos sujeitos em realizar inúmeras atividades, independentemente da idade. Neste caso, destaca-se a importância de incentivar os idosos para que se mantenham realizando atividades, sejam por meio de trabalhos formais ou informais, como também a participação em diferentes grupos sociais. (SCORTEGAGNA; OLIVEIRA, 2015).

Por isso, os idosos desejam, podem e são amparadas pela legislação brasileira, a permanecerem ativas e independentes, tendo em vista que essa é uma fase natural da vida com possibilidades de mudanças e de realizações pessoais como outra qualquer, pois aprender coisas novas, buscar informações, e rever desafios leva o idoso a ter uma melhoria na qualidade de vida. (MACHADO; CHAVES; OLIVEIRA, 2009).

Os autores ainda afirmam que, por isso, cresce a preocupação com temas relacionados à terceira idade. Prova disso são os programas oferecidos pelas instituições de ensino superior através da Universidade Aberta para 
a Terceira Idade. Os programas para a terceira idade oferecem as mais variadas atividades, permitindo, ao idoso, maiores perspectivas de inserção social, além de melhorar consideravelmente sua qualidade de vida - física, intelectual e cultural. (MACHADO; CHAVES; OLIVEIRA, 2009).

Este trabalho surgiu da minha prática enquanto professora de um curso de língua estrangeira (espanhol) para a terceira idade oferecido pela UnATI/PE ${ }^{1}$, pertencente a uma instituição pernambucana de ensino superior.

Assim, a presente pesquisa qualitativa, de cunho bibliográfico, teve por objetivo refletir sobre o processo de motivação para aprender uma língua nova, laços de amizade e envelhecimento ativo, considerando o idoso como protagonista de sua vida.

\section{Universidades Abertas da Terceira Idade no Mundo}

As Universidades Abertas à Terceira Idade (UNATI ou UTI) têm favorecido a implementação de recursos auxiliares, procurando suprir a escassez de projetos sociais e educacionais mais densos e abrangentes para esta faixa etária. Com a intensificação do seu processo de envelhecimento populacional, nos anos 70, França, pelo professor Pierre Vellas, e Estados Unidos foram pioneiros em criar oportunidades educacionais para os idosos, e logo as UNATI espalharam-se por todo o mundo, sendo que a importância desses projetos educacionais passou a ser enfatizada a partir de 1973. (GOMES; LOURES; ALENCAR, 2005; FENALTI; SCHWARTZ, 2003).

Ambos os países procederam a partir de longa tradição de experiências anteriores,

${ }^{1}$ Universidade Aberta à Terceira Idade/ Universidade Federal de Pernambuco. de ordem pública e privada, quanto à educação de adultos, principalmente em alfabetização, preparação para o trabalho e educação para a saúde. (CACHIONI, 1999).

Os atuais programas educacionais para adultos maduros e idosos nos Estados Unidos refletem a história e a herança desses movimentos pioneiros. Na década de 1950, as Universidades de Chicago e Michigan uniram-se a empresas desses Estados e investiram em cursos de preparação para aposentadoria. Esses cursos foram rapidamente difundidos pela América e, nas décadas de 1970 e 1980, desenvolveram-se programas de retreinamento para o trabalhador idoso em muitas empresas. $\mathrm{O}$ interesse pela pesquisa e pelo desenvolvimento de programas orientados para os alunos idosos proliferou por todo o país. Uma rede de instituições de ensino superior e de atividades estava emergindo, enfatizando os resultados positivos da educação para os idosos, visando à atualização cultural dessa população. (CACHIONI, 1999; GOMES; LOURES; ALENCAR, 2005).

Desde 1981, o conceito de autoajuda tem norteado as atividades das universidades da terceira idade na Grã-Bretanha. Em 1994 já havia um total de 240 universidades, distribuídas por Inglaterra, Escócia, País de Gales e Irlanda do Norte, abrangendo 32 mil estudantes. Os programas são flexíveis, considerando-se as necessidades de cada grupo, e geralmente são desenvolvidas atividades educacionais, físicas e recreativas. (CACHIONI, 1999; GOMES; LOURES; ALENCAR, 2005).

Na Nova Zelândia, a primeira universidade da terceira idade (UTI) foi criada sob o modelo inglês, em Auckland, em 1989. Desde então, o programa tem se estendido por todo o país desenvolvendo atividades educacionais e recreativas, procurando 
atender às necessidades da comunidade idosa. (CACHIONI, 1999).

O modelo inglês de autoajuda tem crescido de maneira significativa na República Tcheca, com creca de 45 universidades da terceira idade, desenvolvendo atividades para adultos maduros e idosos. (CACHIONI, 1999).

Em Portugal, o movimento é novo e o primeiro encontro nacional de UTI ocorreu em 1993. No ano seguinte, foi criada uma associação nacional destas universidades. Os programas contam com professores de nível universitário que ensinam sociologia, teologia, história, literatura, artes e artesanato e leitura e escrita. (CACHIONI, 1999).

Na Suíça, essas universidades desenvolvem seus programas conforme o modelo francês. Em todos os estados os idosos participam das atividades oferecidas pelas universidades locais, que priorizam em seus currículos as necessidades desses alunos, assim como na Alemanha, mas nesse país existe uma preocupação dos educadores em desenvolver programas e métodos de ensino especiais, adaptados às necessidades dos idosos. (CACHIONI, 1999; GOMES; LOURES; ALENCAR, 2005).

Já na Polônia, as universidades pertencem a uma associação nacional integrada à Faculdade de Medicina de Varsóvia. Essas universidades desenvolvem suas atividades conforme o modelo francês, particularmente no campo de preparação para aposentadoria. (CACHIONI, 1999; GOMES; LOURES; ALENCAR, 2005).

A maior parte dessas universidades, na Holanda, está localizada nas universidades, seguindo o modelo francês, enquanto em menor número, como em Roosendaal, o modelo inglês de autoajuda promove suas atividades em escolas, universidades e locais de serviço à comunidade. (CACHIONI, 1999).
Percebe-se então, que a UTI é um movimento de grande sucesso em diversos países, uma vez que vem criando oportunidades de desafio intelectual e promovendo bem-estar de adultos maduros e idosos, que estão em busca de um envelhecimento bem-sucedido. Acredita-se, de forma generalizada, que os programas devem servir como um espaço educacional, cultural e político, onde os alunos possam vir a desfrutar de uma vida mais saudável, participativa e produtiva na sociedade em que estão inseridos. (CACHIONI, 1999).

\section{Universidades Abertas da Terceira Idade no Brasil}

O Serviço Social do Comércio (SESC) de São Paulo foi pioneiro na implantação de programas voltados para as pessoas idosas, com programação elaborada com base nos programas de lazer destinados ao preenchimento do tempo livre, em 1960. Anos depois, em 1977, assessorados por gerontólogos da Universidade da Terceira Idade de Toulouse, na França, os técnicos do SESC fundaram a primeira Escola Aberta para a Terceira Idade, primeiro embrião das Universidades da Terceira Idade. (PEIXOTO, 1997; CACHIONI, 1999).

Outras iniciativas foram tomadas a partir da década de 1970, inspiradas no modelo francês, - as chamadas Escolas Abertas para a Terceira Idade cuja população era mais qualificada educacionalmente - e tinham como propósito informar sobre os aspectos biopsicossociais do envelhecimento e preparar para aposentadoria e atualização cultural. (FINATO, 2003).

A partir de então, diferentes instituições universitárias iniciaram o trabalho das UNATI com procedimentos pedagógicos distintos, que vão além da comunicação do saber 
formal científico. Elas visam à valorização pessoal, à convivência grupal, ao fortalecimento da participação social, à formação de um cidadão consciente de suas responsabilidades e direitos, promovendo sua autonomia e qualidade de vida. Assim sendo, os poucos projetos organizados por entidades interessadas pelos idosos são, provavelmente, os únicos instrumentos facilitadores do estabelecimento de relações positivas entre os diversos aspectos da vida do indivíduo na sociedade brasileira. (FENALTI; SCHWARTZ, 2003; CACHIONI, 1999).

Dentre as várias UTI que surgiram no Brasil, destaca-se a da Faculdade de Serviço Social da PUC de Campinas, de São Paulo, que criou, em 1990, um modelo novo de UTI, com um currículo que privilegia as relações intergeracionais, com três níveis de atividades escolares, com duração de um semestre cada e ao final do terceiro semestre, eles recebiam um certificado de conclusão de curso. (PEIXOTO, 1997; GOMES; LOURES; ALENCAR, 2005).

A Universidade de Passo Fundo - RS, em 1991, criou o Centro Regional de Estudos e Atividades para Terceira Idade (CREATI). Em 1996, este programa ultrapassou fronteiras, engajando-se às UNI-3 da América Latina, quando convidou as Universidades Abertas da América Latina para discutir a temática "Educação permanente: Um grande desafio para o século XXI”, no V Encontro LatinoAmericano de Universidades Abertas UNI 3, realizado na cidade de Passo Fundo. Além de Universidades da Terceira Idade brasileiras, sete países da América Latina (Argentina, Bolívia, México, Panamá, Uruguai, Venezuela e Chile) participaram desse encontro. (GOMES; LOURES; ALENCAR, 2005).

Além disso, uma proposta pedagógica para o idoso deve levar em conta, na sua metodologia, outras variáveis como aquelas referente ao processo fisiológico do envelhecimento - a lentidão do raciocínio, a diminuição natural da acuidade visual e auditiva, bem como uma lentidão na mobilidade e na capacidade motora em geral. (FINATO, 2003).

Os elementos essenciais vinculados ao lazer poderiam comungar com os interesses das UNATI, as quais deveriam privilegiar o indivíduo e sua relação com o aprendizado, enfatizando a qualidade do tempo livre do idoso. Portanto, os conteúdos a serem desenvolvidos pelas UNATI devem atender às necessidades e desejos do idoso, norteando o seu desenvolvimento. (FENALTI; SCHWARTZ, 2003).

A tarefa de transmitir ao idoso a importância de preservar a vivência ativa e positiva de seu tempo livre não é nada fácil. Todavia, acredita-se que o idoso possa conscientizar-se da importância do lazer, através da sua integração em projetos que possam transmitir novos valores a este respeito. Desta forma, comungar os conteúdos essenciais do lazer com os projetos organizados nas universidades e/ ou em outras instituições representa um desafio para pesquisadores e profissionais da área do lazer. (FENALTI; SCHWARTZ, 2003).

\section{Universidade Aberta a Terceira Idade da Universidade Federal de Pernambuco e as aulas de língua espanhola}

Dentro da perspectiva da educação permanente e sendo a universidade um lugar por excelência para o aprimoramento, a pesquisa, a busca do conhecimento e também a democratização do saber, timidamente surge em seu âmago um espaço educacional para essa clientela. Para tanto, a Universidade Aberta a Terceira Idade da Universidade Federal de Pernambuco (UnATI/UFPE) é mais uma iniciativa interessante para o enfrentamento 
das questões ligadas ao rápido envelhecimento da população brasileira. (OLIVEIRA; OLIVEIRA, 2006; SOUZA; PURIFICAÇÃO; LIRA, 1999).

Dessa forma, a UnATI/UFPE considera idoso, o indivíduo acima de 60 anos, conforme prescreve a Política Nacional do Idoso (Lei 8.842/1994) Estatuto do idoso (Lei 10.741/2003). Além desse, o referido Estatuto prevê em seu capítulo V, artigo 20, ter o idoso o direito à educação, e, em seu artigo 21 rege que o Poder Público criará oportunidades de acesso do idoso à educação, adequando currículos, metodologias e material didático aos programas educacionais a ele destinados. E, por conseguinte, no seu artigo 25, rege que o Poder Público apoiará a criação de universidade aberta para as pessoas idosas e incentivará a publicação de livros e periódicos, de conteúdo e padrão editorial adequados ao idoso, que facilitem a leitura, considerada a natural redução da capacidade visual. (BRASIL, 1994, 2003).

Com a inserção do idoso na comunidade universitária, a integração entre gerações ocorre necessariamente, fomentando debates sobre as questões que envolvam essa faixa etária, analisando preconceitos e discriminações ora sustentados socialmente e que se apresentam sem fundamentação científica. O próprio idoso, ao se conscientizar de seu espaço na sociedade, terá de si mesmo uma visão mais otimista, considerando-se produtivo, útil, capaz de muito ainda colaborar para a sociedade na qual está inserido. (OLIVEIRA; OLIVEIRA, 2006).

Assim, a UnATI/UFPE iniciou seus trabalhos em 1996, cujo tema em desenvolvimento é o envelhecimento, realizando atividades de ensino, pesquisa e extensão. É um programa financiado pela Pró-Reitoria de Extensão, Cultura e Intercâmbio Científico (PROECIC) da UFPE, a qual é vinculado e possui parcerias, assessorias e convênios com instituições governamentais e não governamentais. (SOUZA; PURIFICAÇÃO; LIRA, 1999).

Basicamente a UnATI estrutura-se em disciplinas $^{2}$ teóricas (abordando as dimensões humanas e sociais) e práticas (envolvem diferentes atividades) de natureza pública/gratuita e caracterizam-se por cursos regulares com duração e frequência semestral. Oferece também seminários, palestras, atividades culturais e de lazer, mesmo que esporadicamente. Além de participar em discussões em nível nacional e internacional sobre políticas para o idoso. (SOUZA; PURIFICAÇÃO; LIRA, 1999).

Dessa forma, o objetivo geral da UnATI/UFPE é a promoção e o incentivo de ações para melhoria da qualidade de vida das pessoas idosas, mediante a realização de cursos que facilitem a aquisição de novos conhecimentos e integração na sociedade contemporânea. Além disso, mobilizam docentes, técnicos, voluntários externos à Instituição e alunos de pós-graduação e graduação para a realização de cursos e outras atividades dirigidas ao segmento idoso. (PROEXC, 2016).

Mas para além disso, a sociedade precisa absorver esta nova realidade de uma população de idosos que só aumentará nos

\footnotetext{
${ }^{2}$ No semestre de 2016.1 foram oferecidos pela UnATI/UFPE os seguintes 29 cursos: alfabetização, automassagem, bainha aberta I, bainha aberta II, bordado em fita, dança do ventre, desconstrução da velhice: identidade e comportamento, espanhol, ética pessoal: um projeto de vida, inglês, introdução à astronomia, introdução a informática I, introdução a informática II, introdução a informática III, introdução a informática IV, yoga, italiano I, italiano II, laboratório da memória, macramê, nutrição e envelhecimento, pedraria, pintura em tecido I, pintura em tecido III, pintura em tela, renascença e tricô, sistema digestório e alimentação saudável e tapeçaria. Nestes cursos, a participação dos idosos varia de acordo com as vagas oferecidas, que giram em torno de 10 a 30 alunos.
} 
próximos anos e que conquistará grandes espaços em diferentes áreas, exigindo sua inclusão total na sociedade, não apenas como usuários de sistemas assistencialistas, voltados a ideia de que idosos precisam ser cuidados, mas também conscientes de que estes são dotados de uma grande potencialidade e capazes de renová-la através do conhecimento permanecendo jovem e mentalmente ativo durante toda a sua vida que vai muito além da vida produtiva, exclusivamente dedicada a uma profissão. (BOIANOSKI; FERNANDES, 2006).

Porém, a UnATI/UFPE está conseguindo se consolidar frente aos seus usuários, percebida pelo aumento significativo de alunos a cada ano. Em 1996 eram 105 inscritos, em 1999 eram 506, onde a grande maioria aproxima-se do Programa através de amigos, se mostrando como uma interessante proposta na busca por soluções para os problemas relacionados às pessoas que se encontram na terceira idade. (SOUZA; PURIFICAÇÃO; LIRA, 1999).

Além do mais, ao longo de quase três anos de trabalho, contou-se com o apoio da Reitoria da UFPE e de outros segmentos da comunidade universitária, a comunidade em geral tem incentivado a continuar e diversificar as atividades, a UnATI/UFPE tem presença garantida nos Fóruns locais e nacionais relacionados ao desenvolvimento das políticas públicas para o idoso e em particular, da Política Nacional de Saúde do Idoso. A imprensa tem divulgado constantemente o Programa, sempre de modo bastante positivo, funcionando como um importante veículo de visibilidade para a questão do envelhecimento em nosso Estado. (BARRETO, 1999).

Diante do exposto, o curso de Língua Espanhol, promovida pela UnATI/UFPE, tem como foco o ensino e o aprofundamento da língua espanhola para pessoas com 60 anos ou mais. O curso é ministrado pela professora voluntária Marina Holanda Kunst, nas instalações da UnATI/UFPE.

As aulas do semestre de 2016, começaram em março/2016 e terminaram em junho/2016, com duração semestral e com aulas as quartas-feiras, de 14:00 as 16:00 (duas horas semanais), com conteúdo programático envolvendo desde gramática, conversação, leitura e compreensão auditiva e escrita.

As aulas são planejadas exclusivamente para alunos idosos, que possuem limitações, por isso, o uso de músicas ou curtas metragens (inseridas na apostila na parte anexa, e também atividades lúdicas que não puderam ser incluídas na apostila), sempre que possível, nas aulas teóricas, foram de fundamental importância para melhorar a compreensão auditiva e leitura, bem como dinamizar as aulas, pois entre os alunos, ficou evidente seus vários objetivos, que variavam entre aprender uma nova língua, melhorar seus conhecimentos, para viajar ou aproveitar as aulas para fazer novas amizades.

O mais interessante de todas as aulas, é que sempre fica uma vontade de aprender mais, de continuar o curso ou fazer o curso novamente, por isso na construção do curso foi importante considerar o perfil dos destinatários como elemento decisivo para o sucesso do curso.

Como apontam Pandofi, Pinto e Teixeira (2008) algumas atitudes são decisivas e devem ser priorizadas na relação entre docente e aluno de terceira idade: o encorajamento e a diminuição de barreiras psicológicas que venham causar inibição ou falta de confiança em si mesmo, portanto, sempre os alunos eram estimulados pela professora para falar sobre o assunto, para conversar, para ler e cantar nos momentos das músicas.

Pois como as autoras ainda afirmam, além de apresentarem mais dificuldade em 
memorizar o novo léxico, e ainda encontraram em seu estudo que os alunos em questão apresentavam um baixo nível de escolaridade e já estavam afastados dos estudos há um bom tempo. Além desse, deve-se considerar as limitações físicas que chegam com a idade como a dificuldade de enxergar, ouvir e até escrever, que exige mais paciência e dedicação do professor para que o aluno não desista de seu intento de aprender um novo idioma e, tampouco, o professor de ensinar. (PANDOFI; PINTO; TEIXEIRA, 2008).

Vale salientar que o comportamento de cada aluno foi mais um desafio a ser conquistado pela professora, pois notou-se que alguns tinham a necessidade de atenção, de gostar de falar e contar suas experiências, enquanto outros alunos eram muito calados e envergonhados, pois quando comparado a outros alunos apresentavam dificuldade na pronuncia.

Convém esclarecer que a professora para ministrar as aulas de língua espanhola para a terceira idade, de nível de pós-graduação, além de atestar proficiência na língua espanhola, também acumulava experiência como docente no curso de mestrado como estagiária à docência, "sabendo que a sala de aula é um espaço de trocas, é um momento mágico de intercâmbio cultural onde se celebra o conhecimento.” (PANDOFI; PINTO; TEIXEIRA, 2008).

\section{Considerações finais}

Ao longo de sua história, as UTIs desenvolveram a vocação de propiciar programas de lazer e programas educativos à população de adultos maduros e idosos, promover pesquisas visando à produção de conhecimentos acerca do processo de envelhecimento, formar profissionais para atuar na área de gerontologia, prestar serviços preventivos de saúde aos idosos e promover a integração entre as gerações. (CACHIONI, 1999).

Portanto, conclui-se que as UTIs são de grande sucesso, uma vez que vêm criando oportunidades de desafio intelectual e promovendo bem-estar a adultos maduros e idosos, que estão em busca de um envelhecimento bem-sucedido. Seus programas devem servir como espaço educacional, cultural e político, em que os alunos possam usufruir de uma vida mais saudável, participativa e produtiva nas sociedades em que estão inseridos. (GOMES; LOURES; ALENCAR, 2005).

Assim, na UnATI/UFPE, se cria, no encontro com o outro, comportamentos, atitudes e hábitos que levam a múltiplas formas de sociabilidade. A rede de relações sociais é tecida pelo contato cotidiano nos cursos e atividades da UnATI/UFPE, cabendo aos alunos escolherem, no conjunto das ofertas, o tipo de participação coletiva, trocando ideias que extrapolam o espaço físico da sala e essa amizade é levada para suas vidas sociais e não mais acadêmica, dentro da UnATI/UFPE.

\section{Referências}

BARRETO, K. M. L. Universidade Aberta à Terceira Idade (UnATI/UFPE): um perfil sócio-epidemiológico dos participantes. Recife, 1999. 146 f. Dissertação (Mestrado em Saúde Pública). Departamento de Saúde Coletiva - NESC, Fundação Oswaldo Cruz Instituto Aggeu Magalhães, Recife, 1999.

BOIANOSKI, C. R.; FERNANDES, P. H. C. $\mathrm{O}$ professor de língua inglesa: ensinando a terceiraidade.In:EDUCERE-CONGRESSO NACIONAL DE EDUCAÇÃO DA PUCPR - PRAXIS, 6., 2006, Curitiba. Anais... Curitiba: Champagnat, 2006. p. 1112-1121. 
BRASIL. Lei 10.741, de 1 de outubro de 2003. Dispõe sobre o Estatuto do idoso. Brasília, 2003.

Lei 8.842, de 4 de janeiro de 1994.

Dispõe sobre a Política Nacional do Idoso. Brasília, 1994.

CACHIONI, M. Universidades da terceira idade: das origens à experiência brasileira. In: NERI, A. L.; DEBERT, G. G. Velhice e sociedade. Campinas: Papirus, 1999.

FENALTI, R. C. S.; SCHWARTZ, G. M. Universidade aberta à terceira idade e a perspectiva de ressignificação do lazer. Revista Paulista de Educação Física, São Paulo, v. 17, n. 2, p. 131-141, jul./dez. 2003.

FINATO, M. da S. S. A universidade aberta à terceira idade $\mathrm{e}$ as redes de apoio afetivo e social do idoso. Marília, 2003. $161 \mathrm{f}$. Tese (Doutorado em Educação). Universidade Estadual Paulista, Marília, 2003.

GOMES, L; LOURES, M. C.; ALENCAR, J. Universidades abertas da terceira idade. Revista História da Educação, Pelotas, v. 9, n.17, p. 119-135, abr. 2005.

MACHADO, H. B.; CHAVES, M. I.; OLIVEIRA, R. C. S. Inglês na terceira idade: um sonho tornando-se realidade. Revista Conexão UEPG, Ponta Grossa, v. 5, n. 1, p. 36-38, 2009.

OLIVEIRA, H. F. de À flor da (terceira) idade: crenças e experiências de aprendizes idosos de língua estrangeira (inglês). Brasília, 2010. 190 f. Dissertação (Mestrado em Linguística Aplicada). Universidade de Brasília, Brasília, 2010.

OLIVEIRA, R. de C.; OLIVEIRA, F. da S. Um novo olhar sobre a terceira idade: a universidade aberta para a terceira idade. In: EDUCERE - CONGRESSO NACIONAL DE EDUCAÇÃO DA PUCPR - PRAXIS,
6., 2006, Curitiba. Anais... Curitiba: Champagnat, 2006. p. 01-13.

PANDOFI, M. A.; PINTO, G. K.; TEIXEIRA, A. Vivências em sala de aula: o ensino-aprendizagem da língua espanhola para a terceira idade. Cadernos de Letras (UFRJ), Rio de Janeiro, n. 24, p. 157-166, mai. 2008.

PEIXOTO, C. De volta às aulas ou de como ser estudante aos 60 anos. In: VERAS, R. P. Terceira idade: desafios para o terceiro milênio. Rio de Janeiro: Relume-Dumará: UnATI/UERJ, 1997.

PROEXC. UNATI. Recife: Universidade Federal de Pernambuco. 2016.

SCORTEGAGNA, P. A.; OLIVEIRA, R. de C. da S. Desenvolvimento socioeducacional em adultos. UNICENTRO, 2015. Disponível em: <http://repositorio.unicentro. br:8080/jspui/bitstream/123456789/988/5/ D E S E N V O L V I M E N T O \% 20 SOCIOEDUCACIONAL \%20E M\% 20 ADULTOS.pdf $>$. Acesso em: 24 ago. 2016.

SOUZA, A. B. de.; PURIFICACAO, A. P. S. da.; LIRA, N. C. de UnAti: reinventando a vida na terceira idade. Recife, 1999, 93 f. Trabalho de Conclusão de Curso (Graduação em Serviço Social), Universidade Federal de Pernambuco, Recife, 1999. 